\title{
A feasibility study of bevacizumab and vinorelbine in patients with previously treated advanced non-squamous non-small-cell lung cancer
}

\author{
KYOHEI KABURAKI, KAZUTOSHI ISOBE, HIROSHI KOBAYASHI, \\ TAKAHIRO YOSHIZAWA, YUJIRO TAKAI and SAKAE HOMMA
}

Division of Respiratory Medicine, Omori Medical Center, Toho University School of Medicine, Tokyo 143-8541, Japan

Received November 1, 2016; Accepted December 19, 2016

DOI: $10.3892 / \mathrm{mco} .2017 .1187$

\begin{abstract}
The aim of this prospective study was to evaluate the efficacy and feasibility of bevacizumab combined with vinorelbine therapy in patients with previously treated non-squamous non-small-cell lung cancer (nonSq-NSCLC). Patients who had received at least one prior chemotherapy course were eligible for this study. The patients were treated with vinorelbine $(25 \mathrm{mg} / \mathrm{kg}$ on days 1 and 8$)$ and bevacizumab (15 mg/kg on day 1), which was repeated every 3 weeks until the development of progressive disease or unacceptable toxicity. Between June, 2011 and January, 2013, 15 patients were enrolled. The response and disease control rates were 26.7 and $73.3 \%$, respectively. The median progression-free survival was 2.1 months and the median overall survival was 34.1 months. Grade 3-4 phlebitis occurred in 3 patients. Therefore, the combination of vinorelbine and bevacizumab was found to be effective in patients with previously treated nonSq-NSCLC, but physicians must be aware of the risk of phlebitis associated with this regimen.
\end{abstract}

\section{Introduction}

Lung cancer is currently the leading cause of cancer-related mortality worldwide. Although certain combinations of chemotherapeutic agents (cisplatin/irinotecan, cisplatin/vinorelbin, cisplatin/gemcitabine and carboplatin/paclitaxel) as first-

Correspondence to: Dr Kazutoshi Isobe, Department of Respiratory Medicine, Omori Medical Center, Toho University School of Medicine, 6-11-1 Omori-Nishi, Ota-ku, Tokyo 143-8541, Japan E-mail: kazutoshiisobe@med.toho-u.ac.jp

Abbreviations: nonSq-NSCLC, non-squamous non-small-cell lung cancer; PFS, progression-free survival; OS, overall survival; $\mathrm{RR}$, response rate; DCR, disease control rate; VEGF, vascular endothelial growth factor; PD, progressive disease; DLT, dose-limiting toxicity

Key words: bevacizumab, vinorelbine, phlebitis line therapy of advanced NSCLC demonstrated similar efficacy (1), the response rate (RR) to chemotherapy is low, with $<40 \%$ of patients exhibiting significant tumor reduction. The 5-year survival remains unacceptably low, in the order of 4-17\% (2).

Bevacizumab is a recombinant humanized monoclonal antibody against vascular endothelial growth factor (VEGF) (3). A number of clinical studies on bevacizumab have been performed, and some demonstrated that the addition of bevacizumab to chemotherapy in the first-line setting significantly increased the progression-free survival (PFS), overall survival (OS) and RR of patients diagnosed with advanced lung cancer (4-10). However, there have been few studies on their feasibility or efficacy of bevacizumab in nonSq-NSCLC patients who were previously treated with a platinum-based regimen.

Vinorelbine, one of the vinca alkaloid agents, was selected to be used with bevacizumab in this regimen for several reasons as follows: Vinorelbine was suggested to possess antiangiogenic properties by preclinical data $(11,12)$. The toxicity profile of vinorelbine is similar to that of bevacizumab, as neither typically causes severe thrombocytopenia or requires corticosteroid premedication. In addition, the present trial was conducted with a lower burden on the patients, as these agents may be administered by injection; therefore, vinorelbine was administered within a few minutes from the time of bevacizumab administration. In addition, two previous phase III trials of single-agent vinorelbine as first-line treatment for elderly patients with advanced NSCLC, revealed that vinorelbine was well-tolerated by elderly patients $(13,14)$. Therefore, a prospective study was conducted to investigate the combination of vinorelbine and bevacizumab in nonSq-NSCLC patients who were previously treated with a platinum regimen.

\section{Patient and methods}

Study design. The present feasibility study was conducted to evaluate the efficacy and safety of vinorelbine and bevacizumab combination therapy in patients with previously treated nonSq-NSCLC. The primary endpoint was feasibility and the secondary endpoints were RR, the incidence of adverse events, OS and PFS. 
Patient eligibility. The Ethics Review Board of Toho University Omori Medical Center approved the present study. The eligibility criteria were as follows: Histological or cytological evidence of NSCLC; prior administration of first-line platinumbased chemotherapy; an interval of at least 4 weeks after the last administration of agents from the prior chemotherapy regimen; no prior administration of vinorelbine or bevacizumab; stage IIIB/IV or recurrent disease after surgery; measurable or assessable disease; Eastern Cooperative Oncology Group performance status (PS) of 0-2; age >20 years; a white blood cell count of $>3 \times 10^{3} / \mu 1$, hemoglobin $(\mathrm{Hb})>9.5 \mathrm{~g} / \mathrm{dl}$, platelet count $>75 \times 10^{3} / \mu 1$, bilirubin $<1.5 \mathrm{mg} / \mathrm{dl}$, aspartate aminotransferase and alanine aminotransferase level $<$ twice the upper limit of normal, creatinine $<1.5 \mathrm{mg} / \mathrm{dl}$ and $\mathrm{PaO}_{2}>70$ Torr; anticipated survival $\geq 3$ months; and provision of written informed consent. The exclusion criteria were as follows: Serious concomitant systemic disorders, including severe heart failure, uncontrollable angina, hypertension, diabetes mellitus, interstitial pneumonia, active infection, ulcer, or another primary malignancy; history of severe hypersensitivity; and pregnancy. All the patients provided written informed consent to participation prior to study enrollment.

Treatment schedule. All the patients received combination therapy with vinorelbine $(25 \mathrm{mg} / \mathrm{kg}$ on days 1 and 8) and bevacizumab (15 mg/kg on day 1$)$. Treatment was performed in 3 -week cycles with vinorelbine and bevacizumab administered on days 1 and 8, and on day 1, respectively. Vinorelbine was scheduled to be administered on day 1 as a 5-min intravenous (i.v.) infusion of $25 \mathrm{mg} / \mathrm{kg}$, followed by a 90 -min i.v. infusion of $15 \mathrm{mg} / \mathrm{kg}$ bevacizumab. If no incident occurred, the second dose was administered over $60 \mathrm{~min}$ and subsequent doses over $30 \mathrm{~min}$. On day 8 of each cycle, only a 5-min i.v. infusion of 25 $\mathrm{mg} / \mathrm{kg}$ vinorelbine was administered. The treatment plan was repeated until the development of progressive disease (PD), unacceptable adverse events, or patient withdrawal of consent. Colony-stimulating factors were used at the doctor's discretion and 5-HT3 antagonists were used as antiemetics.

Treatment schedule amendment. Halfway through the study the treatment schedule was modified to prevent the development of phlebitis. Betamethasone (4.0 mg i.v.) was administered immediately prior to vinorelbine infusion.

Dose adjustment. The criteria for discontinuation of the study included grade 3/4 drug-related toxicity requiring treatment delay of $\geq 3$ weeks, progressive disease, withdrawal of consent, and any changes in the patient's condition that made further treatment inappropriate. The criteria for dose reduction included grade 4 hematological and grade 3 non-hematological toxicity, in which case the vinorelbine dose was reduced by $20 \%$.

Statistical analysis. Tumor response was evaluated using the Response Evaluation Criteria in Solid Tumors, version1.1 (15). All statistical analyses were performed using SPSS statistical software, version 11.0 (SPSS Inc., Chicago, IL, USA). Survival curves were drawn using the Kaplan-Meier method and statistical analysis was performed using the log-rank test. A P-value of $<5 \%$ was considered to indicate statistically significant differences.
Table I. Patient characteristics $(n=15)$.

\begin{tabular}{|c|c|}
\hline Characteristics & No. \\
\hline Age (years) & 68 \\
\hline Median (range) & $57-82$ \\
\hline \multicolumn{2}{|l|}{ Gender } \\
\hline Male & 7 \\
\hline Female & 8 \\
\hline \multicolumn{2}{|l|}{ PS } \\
\hline 0 & 2 \\
\hline 1 & 11 \\
\hline 2 & 2 \\
\hline \multicolumn{2}{|l|}{ Histology } \\
\hline Ad & 15 \\
\hline NOS & 0 \\
\hline \multicolumn{2}{|l|}{ Clinical stage } \\
\hline IV & 7 \\
\hline $\operatorname{Rec}$ & 8 \\
\hline \multicolumn{2}{|l|}{ Smoking history } \\
\hline Current & 6 \\
\hline Former & 9 \\
\hline Never & 0 \\
\hline \multicolumn{2}{|l|}{$E G F R$ mutation } \\
\hline Positive & 5 \\
\hline Negative & 10 \\
\hline \multicolumn{2}{|l|}{ Prior chemotherapy } \\
\hline 1 regimen & 1 \\
\hline 2 regimens & 2 \\
\hline 3 regimens & 2 \\
\hline 4 regimens & 4 \\
\hline$\geq 5$ regimens & 6 \\
\hline Platinum doublet (+/-) & $14 / 1$ \\
\hline EGFR-TKI (+/-) & $5 / 10$ \\
\hline \multicolumn{2}{|l|}{ Single agent $(+/-)$} \\
\hline $\operatorname{PEM}(+/-)$ & $9 / 6$ \\
\hline DTX (+/-) & $2 / 13$ \\
\hline GEM (+/-) & $3 / 12$ \\
\hline CPT-11 (+/-) & $1 / 14$ \\
\hline
\end{tabular}

PS, performance status; Ad, adenocarcinoma; NOS, not otherwise specified; Rec, recurrence after surgical resection; EGFR, epidermal growth factor receptor gene; TKI, tyrosine kinase inhibitor; PEM, pemetrexed; DTX, docetaxel; GEM, gemcitabine; CPT-11, irinotecan.

This single-center study was conducted at the Toho University Omori Medical Center (Tokyo, Japan) and was approved by its Human Genome/Gene Analysis Research Ethics Committee (authorization number, 22-86).

\section{Results}

Patient characteristics. Between June, 2011 and January, 2013, a total of 15 patients with nonSq-NSCLC were enrolled in this 
study. All the patients were evaluable for toxicity and response assessment. The patient characteristics are presented in Table I. Of the 15 patients, $12(80 \%)$ had received at $\leq 3$ prior courses of chemotherapy and all the patients had a PS of $0-2 ; 5$ patients harbored a mutation of the epidermal growth factor receptor gene conferring sensitivity to tyrosine kinase inhibitors.

Treatment administration. Overall, a total of 68 cycles were administered (median, 4; range, 1-12) and 8 patients required a dose reduction due to toxicity. The reasons for treatment discontinuation included disease progression $(n=11)$, toxicity $(n=3)$ and the patient's wishes $(n=1)$.

Treatment efficacy. All the patients were evaluable. There was no complete response and 4 patients exhibited a partial response, accounting for an overall RR of $26.7 \%$ (95\% CI: 1.3-52.3). Another 7 patients exhibited stable disease as their best response, resulting in an overall disease control rate (DCR) of $73.3 \%$ (95\% CI: 47.98-98.68; Table II). The Kaplan-Meier curve for PFS is shown in Fig. 1; the estimated median PFS was 2.1 months (95\% CI: 1.2-4.6 months). The Kaplan-Meier curve for OS is shown in Fig. 2; the median OS was 34.1 months (95\% CI: 15.6-52.6 months) and the 1-year OS rate was $78.6 \%$.

Treatment toxicity. All the patients ware evaluable for toxicity. The adverse events of this study are summarized in Table II. The incidence of grade 3-4 neutropenia, anemia and febrile neutropenia was 53.3, 6.7 and $6.7 \%$, respectively. The incidence of grade 3-4 nausea/vomiting and anorexia was 6.7 and $13.3 \%$, respectively. Grade 3-4 phlebitis occurred in 3 patients (20\%); phlebitis improved by placement of a central venous catheter in 1 patient and by administration of corticosteroid treatment in 2 other patients. There were no reported grade 3/4 bevacizumab-related adverse events, such as thrombosis, hemorrhage, bowel perforation, hypertension, proteinuria, or hemorrhagic events.

\section{Discussion}

The tolerability and efficacy of bevacizumab combined with vinorelbine were evaluated in patients receiving second-line therapy for recurrent NSCLC. The study demonstrated an overall RR of $26.7 \%$ and an overall DCR of $73.3 \%$. The median PFS was 2.1 months and the median OS was 34.1 months.

Several studies on doublet chemotherapy including bevacizumab as second-line chemotherapy for NSCLC have been reported (16-19). Herbst et al (20) conducted a randomized second-line phase II study that evaluated the efficacy of bevacizumab in combination with standard second-line chemotherapies that included pemetrexed, docetaxel or erlotinib, and it demonstrated a RR of $12.5 \%$, a median PFS of 4.8 months and an OS of 12.6 months in the bevacizumab plus chemotherapy arm. Our study results included an RR of $26.7 \%$, a median PFS of 2.1 months and a median OS of 34.1 months. These values were better compared with the abovementioned historical data for second-line chemotherapy. A limitation of the present study was that it was conducted on a highly selected patient group and our patient sample was insufficient for accurate evaluation. The aim of this study was to
Table II. Adverse events $(n=15)$.

\begin{tabular}{lrc}
\hline & \multicolumn{2}{c}{ NCI CTC } \\
\cline { 2 - 3 } Toxicities & Grade $1 / 2(\%)$ & Grade $3 / 4(\%)$ \\
\hline Hematological & & \\
Leukopenia & 13.3 & 33.3 \\
Neutropenia & 40.0 & 53.3 \\
Anemia & 20.0 & 6.7 \\
Thrombocytopenia & & 0.0 \\
Non-hematological & 13.3 & \\
Nausea/vomiting & 6.7 & 6.7 \\
Anorexia & 0.0 & 13.3 \\
Diarrhea & 26.6 & 0.0 \\
Phlebitis & 33.3 & 20.0 \\
Rash & 0.0 & 0.0 \\
Hemorrhage & 0.0 & 0.0 \\
Febrile neutropenia & 33.3 & 0.0 \\
Hypertension & & \\
\hline
\end{tabular}

NCI CTC, National Cancer Institute Common Terminology Criteria.

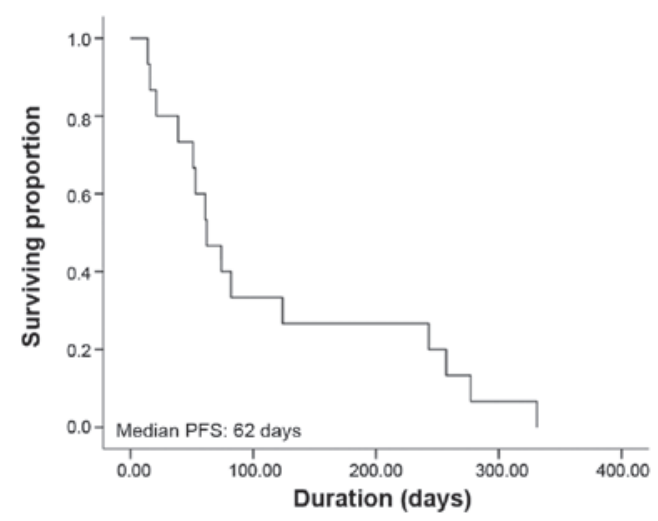

Figure 1. The median progression-free survival was 62 days.

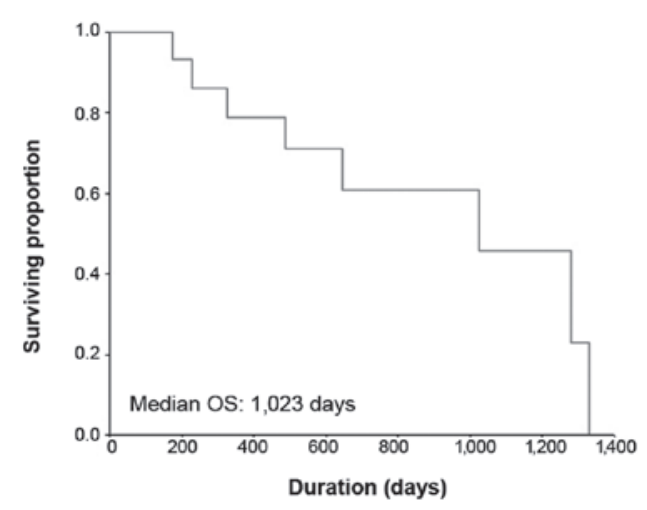

Figure 2. The median survival time was 1,023 days.

investigate the feasibility and effectiveness of third-generation chemotherapy with bevacizumab. Vinorelbine was selected as the other third-generation chemotherapeutic agent, as it is 
a vinca alkaloid with barely any reported adverse events in previous second-line studies (21).

In terms of adverse events, there was a high rate of severe phlebitis. Several studies have reported that bevacizumab has enhanced the toxicity and increased the activity of another agent in a combination regimen $(22,23)$. Bevacizumab targets VEGF and alters tumor vessel physiology, thereby increasing intratumoral drug uptake $(24,25)$. Seto et al (7) reported that the addition of bevacizumab may increase the toxicity to a certain degree (hypertension, proteinuria and haemorrhagic events).

Adverse events were carefully monitored, particularly phlebitis; therefore, halfway through the study, steroids were administered as a preventive measure against the development of phlebitis, however, 2 of 7 patients who received steroid treatment as a precaution developed phlebitis; thus, the preventive effect of steroids was not confirmed. In our study, the combination therapy enhanced the typical adverse events associated with cytotoxic anticancer drugs, although not those particularly associated with bevacizumab, such as hypertention, proteinuria and bleeding. These results are similar to previous findings on the adverse events of bevacizumab combined with other agents (4-10). The bevacizumab and vinorelbine combination therapy was considered as high-risk in terms of phlebitis or vascular events; thus, further phase II studies on bevacizumab combined with vinorelbine are required.

The aim of the AvaALL study, which is an open-label, randomized, multicenter phase III study, is to evaluate the efficacy and safety of bevacizumab in combination with standard of care treatment in patients with nonSq-NSCLC (26). Patients will be randomly assigned to one of two treatment arms to receive either bevacizumab plus standard chemotherapy or standard chemotherapy alone, from the first- through to the third-line setting. The result of this study may indicate that new treatment strategies should be established for previously treated nonSq-NSCLC patients.

In conclusion, combination treatment with vinorelbine and bevacizumab may prove to be effective and feasible for patients with previously treated nonSq-NSCLC. However, this regimen should be managed carefully due to the associated adverse events, particularly the increased risk of phlebitis.

\section{References}

1. Ohe Y, Ohashi Y, Kubota K, Tamura T, Nakagawa K, Negoro S, Nishiwaki Y, Saijo N, Ariyoshi Y and Fukuoka M: Randomized phase III study of cisplatin plus irinotecan versus carboplatin plus paclitaxel, cisplatin plus gemcitabine, and cisplatin plus vinorelbine for advanced non-small-cell lung cancer: Four-Arm Cooperative Study in Japan. Ann Oncol 18: 317-323, 2007.

2. Hirsch FR, Scagliotti GV, Mulshine JL, Kwon R, Curran WJ Jr, Wu YL and Paz-Ares: Lung cancer: current therapies and new targeted treatments 389: 299-311, 2017

3. Giaccone G: The potential of antiangiogenic therapy in non-small cell lung cancer. Clin Cancer Res 13: 1961-1970, 2007.

4. Sandler A, Gray R, Perry MC, Brahmer J, Schiller JH, Dowlati A, Lilenbaum R and Johnson DH: Paclitaxel-carboplatin alone or with bevacizumab for non-small-cell lung cancer. N Engl J Med 355: 2542-2550, 2006.

5. Zhou C, Wu YL, Chen G, Liu X, Zhu Y, Lu S, Feng J, He J, Han B, Wang J, et al: BEYOND: A randomized, double-blind, placebo-controlled, multicenter, phase III study ofFirst-Line carboplatin/paclitaxel plus bevacizumab or placebo in chinese patients with advanced or recurrent nonsquamous non-small-cell lung cancer. J Clin Oncol 33: 2197-2204, 2015.
6. Galetta D, Cinieri S, Pisconti S, Gebbia V, Morabito A, Borsellino N, Maiello E, Febbraro A, Catino A, Rizzo P, et al: Cisplatin/ Pemetrexed Followed by Maintenance Pemetrexed Versus Carboplatin/Paclitaxel/Bevacizumab Followed by Maintenance Bevacizumab in Advanced Nonsquamous Lung Cancer: The GOIM (Gruppo Oncologico Italia Meridionale) ERACLE Phase III Randomized Trial. Clin Lung Cancer 16: 262-273, 2015.

7. Seto T, Kato T, Nishio M, Goto K, Atagi S, Hosomi Y, Yamamoto N, Hida T, Maemondo M, Nakagawa K, et al: Erlotinib alone or with bevacizumab as first-line therapy in patients with advanced non-squamous non-small-cell lung cancer harbouring EGFR mutations (JO25567): An open-label, randomised, multicentre, phase 2 study. Lancet Oncol 15: 1236-1244, 2014.

8. Niho S, Kunitoh H, Nokihara H, Horai T, Ichinose Y, Hida T, Yamamoto N, Kawahara M, Shinkai T, Nakagawa K, et al; JO19907 Study Group: Randomized phase II study of first-line carboplatin-paclitaxel with or without bevacizumab in Japanese patients with advanced non-squamous non-small-cell lung cancer. Lung Cancer 76: 362-367, 2012.

9. Herbst RS, Ansari R, Bustin F, Flynn P, Hart L, Otterson GA, Vlahovic G, Soh CH, O'Connor P and Hainsworth J: Efficacy of bevacizumab plus erlotinib versus erlotinib alone in advanced non-small-cell lung cancer after failure of standard first-line chemotherapy (BeTa): A double-blind, placebo-controlled, phase 3 trial. Lancet 377: 1846-1854, 2011.

10. Reck M, von Pawel J, Zatloukal P, Ramlau R, Gorbounova V, Hirsh V, Leighl N, Mezger J, Archer V, Moore N, et al: Phase III trial of cisplatin plus gemcitabine with either placebo or bevacizumab as first-line therapy for nonsquamous non-small-cell lung cancer: AVAil. J Clin Oncol 27: 1227-1234, 2009.

11. Vacca A, Iurlaro M, Ribatti D, Minischetti M, Nico B, Ria R, Pellegrino A and Dammacco F: Antiangiogenesis is produced by nontoxic doses of vinblastine. Blood 94: 4143-4155, 1999.

12. Kruczynski A, Poli M, Dossi R, Chazottes E, Berrichon G, Ricome C, Giavazzi R, Hill BT and Taraboletti G: Antiangiogenic, vascular-disrupting and anti-metastatic activities of vinflunine, the latest vinca alkaloid in clinical development. Eur J Cancer 42: 2821-2832, 2006.

13. Gridelli C, Perrone F, Gallo C, Cigolari S, Rossi A, Piantedosi F, Barbera S, Ferraù F, Piazza E, Rosetti F, et al; MILES Investigators: Chemotherapy for elderly patients with advanced non-small-cell lung cancer: The Multicenter Italian Lung Cancer in the Elderly Study (MILES) phase III randomized trial. J Natl Cancer Inst 95: 362-372, 2003.

14. No authors listed: Effects of vinorelbine on quality of life and survival of elderly patientswith advanced non-small-cell lung cancer. The Elderly Lung Cancer VinorelbineItalian Study Group. J Natl Cancer Inst 91: 66-72, 1999.

15. Therasse P, Arbuck SG, Eisenhauer EA, Wanders J, Kaplan RS, Rubinstein L, Verweij J, Van Glabbeke M, van Oosterom AT, Christian MC, et al: New guidelines to evaluate the response to treatment in solid tumors. European Organization for Research and Treatment of Cancer, National Cancer Institute of the United States, National Cancer Institute of Canada. J Natl Cancer Inst 92: 205-216, 2000.

16. Weiss JM, Villaruz LC, Socinski MA, Ivanova A and Grilley-Olson J: Dhruva N andStinchcombe TE: A singlearm phase II trial of pazopanib in patients with advanced non-small cell lung cancer with non-squamons histology with disease progression on bevacizumab containing therapy. Lung Cancer 86: 288-290, 2014.

17. Powell SF, Beitinjaneh A, Tessema M, Bliss RL, Kratzke RA, Leach J, Dudek AZ and Phase II: Phase II study of topotecan and bevacizumab in advanced, refractory non--small-cell lung cancer. Clin Lung Cancer 14: 495-501, 2013.

18. Kubota T, Okano Y, Sakai M, Takaoka M, Tsukuda T, Anabuki K, Kawase S, Miyamoto S, Ohnishi H, Hatakeyama N, et al: Carboplatin plus Weekly Paclitaxel with Bevacizumab for First-line Treatment of Non-small Cell Lung Cancer. Anticancer Res 36: 307-312, 2016.

19. Ohyanagi F, Yanagitani N, Kudo K, Kawano Y, Sakatani T, Tanimoto A, Nishizawa H, Horiike A, Hagiwara S, Horai T, et al: Phase II study of docetaxel-plus-bevacizumab combination therapy in patients previously treated for advanced non-squamous non-small cell lung cancer. Anticancer Res 34: 5153-5158, 2014.

20. Herbst RS, O'Neill VJ, Fehrenbacher L, Belani CP, Bonomi PD, Hart L, Melnyk O, Ramies D, Lin M and Sandler A: Phase II study of efficacy and safety of bevacizumab in combination with chemotherapy or erlotinib compared with chemotherapy alone for treatment of recurrent or refractory non small-cell lung cancer. J Clin Oncol 25: 4743-4750, 2007. 
21. Kosmas C, Tsavaris N, Panopoulos C, Vadiaka M, Stavroyianni N, Kourelis T, Malamos N, Antonopoulos M and Kalofonos HP: Gemcitabine and vinorelbine as second-line therapy in non-smallcell lung cancer after prior treatment with taxane+platinum-based regimens. Eur J Cancer 37: 972-978, 2001

22. Yoshida M, Muro K, Tsuji A, Hamamoto Y, Yoshino T, Yoshida K, Shirao K, Miyata Y, Takahari D, Takahashi T, et al: Combination chemotherapy with bevacizumab and S-1 for elderly patients with metastatic colorectal cancer (BASIC trial). Eur J Cancer 51: 935-941, 2015.

23. Pujol JL, Lavole A, Quoix E, Molinier O, Souquet PJ, F, Le Caer H, Moro-Sibilot D, Fournel P, Oster JP, et al: French Cooperative Thoracic Intergroup (IFCT); FrenchCooperative Thoracic Intergroup IFCT. Randomized phase II-III study ofbevacizumab in combination with chemotherapy in previously untreated extensivesmall-cell lung cancer: Results from the IFCT-0802 trial. Ann Oncol 26: 908-914, 2015.

24. Wildiers H, Guetens G, De Boeck G, Verbeken E, Landuyt B, Landuyt W, de Bruijn EA and van Oosterom AT: Effect of antivascular endothelial growth factor treatment on the intratumoral uptake of CPT-11. Br J Cancer 88: 1979-1986, 2003.
25. Dickson PV, Hamner JB, Sims TL, Fraga CH, Ng CY, Rajasekeran S, Hagedorn NL, McCarville MB, Stewart CF and Davidoff AM: Bevacizumab-induced transient remodeling of the vasculature in neuroblastoma xenografts results in improved delivery and efficacy of systemically administered chemotherapy. Clin Cancer Res 13: 3942-3950, 2007.

26. Gridelli C, Bennouna J, de Castro J, Dingemans AM, Griesinger F, Grossi F, Rossi A, Thatcher N, Wong EK and Langer C: Randomized phase IIIb trial evaluating the continuation of bevacizumab beyond disease progression in patients with advanced non-squamous non-small-cell lung cancer after first-line treatment with bevacizumab plus platinum-based chemotherapy: Treatment rationale and protocol dynamics of the AvaALL (MO22097) trial. Clin Lung Cancer 12: 407-411, 2011. 